\title{
Liver Disease and Fasting during the Month of Ramadan
}

\section{Staff Members of Tropical Medicine Department, Faculty of Medicine, Zagazig Universty,Egypt}

BACKGROUND

The fasting during the month of Ramadan is an integral part of the Islamic believes. During this month Moslems begins daily fasting from the time of dawn to the time sunset in a continuum. This month is a lunar month that rotates throughout the seasons of the year. Although Ramadan fasting is safe for all healthy individuals with no adverse effects on the heart, lung, liver, kidney, eyes, hematologic profile, endocrine and neuropsychiatric functions, those with various diseases should consult specialist for the possibility of fasting [1]. This year fasting in Ramadan bears peculiars including the very long day time of about 16 hours, its occurrence in the summer time and during the month of July. This hot atmosphere exposes not only patients with chronic liver diseases but also the general populations to excessive sweating and possibly the problems of electrolytes disturbances.

The spectrum of liver diseases in the Egyptian community is wide ranging from self limited acute hepatitis to liver cirrhosis and hepatocellular carcinoma (HCC). We commonly see many patients with liver diseases who willing and sometimes insist to fast.

The staff members in the Department of Tropical Medicine, Zagazig University, Egypt through a panel discussion shaded the light on this issue. We knew that the level of evidence regarding the following recommendations is very weak because the scarcity of the studies focusing this subject, but it is necessary to formulate a roadmap to help clinicians as well as patients to decide who can fast without harm.

\section{ACUTE HEPATITIS}

The panelists recommended that all patients of acute hepatitis should never fast. Some experts reported delayed recovery of serum bilirubin and liver enzymes in some patients who insisted to fast; indeed rapid recovery occurred when the oral diet resumed. These patients needs frequent light diet and they should avoid fasting.

\section{CHRONIC HEPATITIS}

There is a consensus among our staff that all patients with chronic hepatitis of any etiology without associated co-morbidities and with good liver functions can tolerate fasting. The evidence comes from previous studies [2] and also from the personal experience. Furthermore, patients with chronic viral hepatitis under interferon (IFN) therapy should be separately evaluated. Patients under IFN therapy but without side effects can tolerate fasting although are advised to avoid fasting in the day of IFN injection to avoid exhaustion and dehydration. Whereas, patients under IFN therapy but with major side effects should avoid fasting.

\section{BILHARZIAL HEPATIC FIBROSIS}

There is a consensus among our staff that all patients with bilharzial hepatic fibrosis without esophageal varices can tolerate fasting.

\section{LIVER CIRRHOSIS}

This category of liver diseases is of particular importance not only because it's high prevalence in Egypt, but mainly because patients with liver cirrhosis are prone to rapid deterioration and development of many complications. Although, the patients may feel better due improvement of their dyspeptic symptoms with fasting; their liver became exhausted.

\section{Compensated cirrhosis}

Patients with Child A cirrhosis who have good liver function can fast. Some staff recommends that patients of this category should adhere to certain precautions including but not limited to: they should receive good amounts of fluids containing electrolytes and sugar throughout the night time, should avoid direct exposure to sun light, should practice moderate activity jobs, should never delay Iftar and should delay Sohoor to the time dawn. Others recommend that patients may be re-evaluated after 10 days from fasting for both clinical and laboratory parameters. Patients who are reported as liver functions Child A but with history of any previous decompensation e.g. ascites, encephalopathy, upper GIT bleeding....etc should avoid fasting. The issue of upper GIT bleeding was evaluated in many studies. It 
seems that Fasting during Ramadan increase bleeding from peptic ulcer [3-5]. Variceal bleeding and fasting in Ramadan was recently studied, it seems that fasting cirrhotics have less frequency of variceal bleeding when compared with non-fasting [2,3] and this may be explained by the increased venous flow with the regular diet [6].

\section{Decompensated cirrhosis}

Patients of liver cirrhosis with Child B and C class, should never fast. Indeed, several reports of adverse events had been reported including the increasing ascites, edema, hepatic encephalopathy, muscle cramps, and variceal bleeding [1].

\section{HEPATOCELLULAR CARCINOMA}

There is a consensus among our staff that all patients with HCC should never fast. This is applied for patients with hepatic solitary or multiple focal lesions as well as advanced HCC. In fact, those patients are prone to hypoglycemia due to many reasons including the demand for glucose by an enormous tumour mass, reduced level of glucose-6phosphatase and phosphorylase, and increased levels of insulin-like growth factor II than in normal liver [7].

\section{FUTURE PERSPECTIVE}

We aim to conduct prospective studies to evaluate the impact of continuous fasting on different types of liver diseases. We also will operate with other colleagues from different Egyptian institutions to update these recommendations and strengthen the level of evidence regarding each recommendation.

\section{REFERENCES}

1- Azizi F. Islamic Fasting and Health. Ann Nutr Metab 2010;56:273-82

2-Elnadry MH, Nigm IA, Abdel Aziz IM, Elshafee AM, Elazhary SS, Abdel Hafeez MA, et al. Effect of Ramadan fasting on Muslim patients with chronic liver diseases. J Egypt Soc Parasitol 2011;41:337-46.

3- Amine ElM, Kaoutar S, Ihssane M, Adil I, Dafr-Allah B. Effect of Ramadan fasting on acute upper gastrointestinal bleeding. J Res Med Sci 2013;18:230-33.

4- Hosseini-Asl K, Rafieian-Kopaei M. Can patients with active duodenal ulcer fast Ramadan? Am J Gastroenterol 2002;97:2471-2.

5- Emami M, Rahimi H. Effects of Ramadan fasting on acute upper gastrointestinal bleeding due to peptic ulcer. J Res Med Sci 2006;11:170-5. 6- Sugano S, Yamamoto K, Takamura N, Momiyama K, Watanabe M, Ishii K. Azygos venous blood flow while fasting, postprandially, and after endoscopic variceal ligation, measured by magnetic resonance imaging. J Gastroenterol 1999;34:310-4

7- Sherlock S, Dooley J. Malignant Liver Tumours. In Diseases of the Liver and Biliary System, $11^{\text {th }}$ edition, Blackwell Science Ltd, 2002:537. 